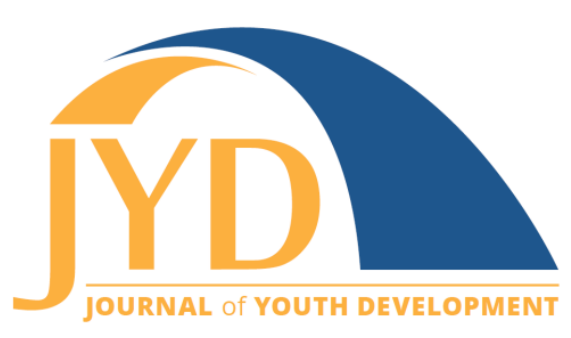

http://jyd.pitt.edu/ | Vol. 15 Issue 3 DOI 10.5195/jyd.2020.951 | ISSN 2325-4017 (online)

\title{
Commentary on Recent Consensus Studies From the Board on Children, Youth, and Families
}

\author{
Richard F. Catalano \\ Social Development Research Group, School of Social Work, University of Washington \\ catalano@uw.edu
}

\begin{abstract}
In this thought leader commentary, the author makes observations about the findings and recommendations noted in this special issue. The broad scope of these reports from bullying; mental, emotional, and behavioral health; English language and dual language learners; optimal development; the promise of adolescence; optimal health; and shaping summertime experiences enhances our perspective on the important developmental time of childhood, adolescence, and young adulthood. Two broad perspectives-positive youth development and distinctive risky behaviors-are highlighted among other important themes. The author observes that the Board on Children, Youth, and Families of the National Academies of Sciences, Engineering, and Medicine could add value in synthesizing the implications of these studies for federal, state, and local agencies; communities; and the youth population itself, identifying both commonalities and research gaps across these reports. Such a synthesis could provide a roadmap including common and unique predictors, evidence-based interventions to address these predictors, and perspectives on integrative and complementary aspects of community, state, and federal systems. Advocacy is needed to take evidence summarized in these reports to scale. In this context, evidence-based practices from promotion to treatment backed by new implementation research in scale-up are likely to return immense benefits to society.
\end{abstract}

Key words: consensus studies; Board on Children, Youth, and Families; National Academies of Sciences, Engineering, and Medicine; prevention science; positive youth development; scale-up; promotion science

This issue of the Journal of Youth Development is graced with summary articles on recent reports from consensus studies from the Board on Children, Youth, and Families of the National Academies of Science, Engineering, and Medicine (the National Academies). Graced because the highlights of these consensus studies are all in one place in a quickly digestible form, providing readers with the power of the National Academies process, as well as the developmental

(c) $\mathbf{E Y}$ New articles in this journal are licensed under a Creative Commons Attribution 4.0 License. This journal is published by the University Library System, University of Pittsburgh and is cosponsored by the University of Pittsburgh Press. The Journal of Youth Development is the official peer-reviewed publication of the National Association of Extension 4-H Agents and the National AfterSchool Association. 


\section{Commentary on Recent Consensus Studies}

grouping of reports and recommendations on children and youth. I will make a few observations about these findings and recommendations, not on a comprehensive basis that will involve a broader Board on Children, Youth, and Families process, but from my perspective garnered from a 40 -year career in prevention and promotion science.

First, the wide scope of these reports from bullying; mental, emotional, and behavioral health; English language and dual language learners; optimal development; the promise of adolescence; optimal health; and shaping summertime experiences enhances our perspective on the important developmental time of childhood, adolescence, and young adulthood. Expansive developmental periods are covered from preconception through young adulthood. While not a strictly developmental textbook, the reports collectively provide a good overview of critical issues and evidence-based interventions-programs and policies--that affect this time of development.

Second, two broad perspectives are provided across the reports. These include positive youth development and distinctive risky behaviors. Most of the reports describe positive, healthy, or optimal developmental outcomes. The reports focus on a range of positive developmental experiences, including promotion of mental, emotional, and behavioral health; physical health; decision making; dual language learning; cognitive skill development; and how summertime experiences might enhance positive development. Focusing on promoting positive development highlights the advantages of health promotion and universal and selective prevention, and how particular experiences, structural changes, and interventions can enhance positive development.

The second perspective is on distinctive risky behaviors like bullying, substance use, and mental and emotional problems. The risky behavior perspective recognizes that risky behavior can interfere with healthy development and can't be ignored. In these reports, this perspective is provided across development, and helps diverse specialties understand the common sources of risk behaviors in children and adolescence. The two perspectives-positive youth development and risky behavior-addressed in these reports provide the field with better cross-cutting solutions for both problem as well as healthy development. Together these two perspectives provide an enriched sense of the need for cross-sector action and responsibilities to improve outcomes for children and youth.

Third, most of the articles summarizing the consensus studies focus on the etiology of positive and problem behaviors in order to understand the potential solutions of promotion, prevention, 


\section{Commentary on Recent Consensus Studies}

and intervention. The levels of predictors of both positive and problem behavior identified would make Urie Bronfenbrenner, J. David Hawkins, and Thomas McKeown proud! Later positive and problem outcomes are produced by a variety of experiences and conditions, including individual predictors such as those "under the skin," e.g., brain development, epigenetics, and hypothalamic pituitary adrenal (HPA) systems. These also include individual predictors influenced by experiences of individuals interacting with their environment, including competencies and reinforcement experiences.

Importantly, each of the articles also identifies social and structural predictors in the family and school, peer, community, and larger societal environments that affect both positive and problem development. When these precursors are consistently predictive (demonstrated longitudinally), malleable (can be changed), and are not spurious (best demonstrated through experimental manipulation), they can provide important information about possible interventions (policies and programs) to reduce precursors that increase problem development and strengthen precursors that increase positive development. The wide variety of potential predictors across problems represented in these reports is ripe for a consensus study on the shared and unique predictors of child and adolescent positive and problem development. This could help immeasurably with the problem discussed next.

Fourth, most of the reports of the consensus studies suggest that child and adolescent development is impacted by multiple systems in the environment. These systems often have specific goals and often do not interact in ways that recognize the collective community or societal goal of producing healthy children, youth, and young adults. Most reports call for crosssystems thinking. One of the reports provides several models for how this can be accomplished, specifically the implementation science chapters of the Fostering Healthy Mental, Emotional, and Behavioral Development in Children and Youth (MEB Health) report. Further, several reports like the Shaping Summertime Experiences: Opportunities to Promote Healthy Development and Well-Being for Children and Youth (MEB Health), and the Promoting the Educational Success of Children and Youth Learning English: Promising Futures report call for more cross-development thinking, research that monitors the impact of interventions across development, and research that examines the impact of interventions that are delivered across multiple years or developmental periods. The new consensus study, MEB Health, on shared and unique predictors mentioned above could help provide multiple systems and caregiving institutions with common and unique targets to promote healthy development. This scientific 


\section{Commentary on Recent Consensus Studies}

base could help systems integrate and provide complimentary services for more effective healthy development and problem reduction for all children, adolescents, and young adults.

Fifth, most of the reports describe that predictors of problem and positive development are concentrated in disadvantaged areas and groups (e.g., low-income families; people of color; lesbian, gay, bisexual, transgender, and queer (LGBTQ); immigrants; those who reside in rural environments), creating geographical, cultural, and racial pockets of high risk and low protection. Many of these reports document that this, in turn, leads to much less favorable outcomes for children and youth, as well as health disparities on a number of developmental outcomes (see Lu and Halfon, 2003, p. 18 for a graphic example). This concentration calls for a new approach to resource distribution to enhance equity. This includes two-generation approaches, to incorporate high-risk, low-protection areas or populations as a criterion for resource distribution, as well as policies to address and reduce poverty.

There are other important common aspects of these articles, including the recommendation of evidence-based policies, programs, and practices in fields where there is sufficient evidence. One of the important aspects of National Academies consensus studies is that these studies explicitly report where there is insufficient evidence on particular aspects of the statement of task to the committee. Even when the study's charge may be looking for support of a particular position, the National Academies report process can be counted on to state where there is evidence and where evidence is lacking. In developing fields where there has not been sufficient research, consensus studies utilize workshops of practitioners and scientists who are exploring these developing areas to hear about new and promising directions that need more research.

As the MEB Health report suggests, implementation science has matured over the last 15 years. Implementation science is the study of what elements increase the likelihood that interventions tested in efficacy trials can be replicated and go to widespread scale, while still demonstrating the effects confirmed in the efficacy trials. This science is critical to improving the health of children, adolescents, and young adults. Despite the evidence of efficacy trials, there are many real-world conditions that must be aligned to provide effects at scale in new settings and with diverse populations. Given the number of efficacious policies and programs identified across reports, it is my opinion that it is essential, if we are concerned about the public's health, that more replication, scale-up implementation research be conducted. 
In closing, the Board on Children, Youth, and Families of the National Academies could add value in synthesizing the implications of these studies for federal, state, and local agencies; communities; and the youth population itself, identifying both commonalities and research gaps across these reports. Such a synthesis could provide a roadmap including common and unique predictors; evidence-based interventions to address these predictors; and perspectives on integrative and complementary aspects of community, state, and federal systems. Advocacy is needed to take evidence summarized in these reports to scale. In this context, evidence-based practices from promotion to treatment backed by new implementation research in scale-up are likely to return immense benefits to society.

\section{References}

Lu, M. C., \& Halfon, N. (2003). Racial and ethnic disparities in birth outcomes: A life-course perspective. Maternal and Child Health Journal, 71 ), 13-30. https://doi.org/10.1023/a:1022537516969 